\title{
Rethinking political distrust
}

\author{
Eri Bertsou(1) \\ Political Science Department, University of Zurich, Zurich, Switzerland \\ E-mail: bertsou@ipz.uzh.ch
}

(Received 10 April 2018; revised 20 March 2019; accepted 30 March 2019)

\begin{abstract}
Increasing political distrust has become a commonplace observational remark across many established democracies, and it is often used to explain current political phenomena. In contrast to most scholarship that focuses solely on the concept of trust and leaves distrust untheorized, this article makes a contribution by analysing political distrust. It argues that citizen distrust of government and political institutions poses a threat for democratic politics and clarifies the relationship between the distrust observed in established democracies and classical 'liberal distrust', which is considered beneficial for democracy. Further, it addresses the relationship between trust and distrust, identifying a series of functional asymmetries between the two concepts, with important implications for theoretical and empirical work in political science. The article suggests that a conceptualization of political distrust based on evaluations of incompetence, unethical conduct and incongruent interests can provide a fruitful ground for future research that aims to understand the causes, consequences, and potential remedies for political distrust.
\end{abstract}

Keywords: political trust and distrust; liberal distrust; democratic stability; political attitudes

\section{Introduction}

A wide range of political phenomena across established democracies in the past decade have been described or explained as manifestations of citizen distrust towards political institutions, politicians, and often the entire political system. From the mobilization and protests following the 2008 financial crisis, to more recent political developments such as Trump's election to the US Presidency, British voters' decision to exit the European Union and the rise in support for populist or extreme political parties in France, the Netherlands and even Germany, the prevailing citizen sentiments towards politics are distinctively negative. A building consensus among political commentators and scholars of public opinion is that citizens are 'pissed off with politics, that they distrust the political system and the political establishment, and that they are prepared to break the rules and reject mainstream parties and politicians (Hetherington and Rudolph, 2015; Jennings and Stoker, 2015).

Given the extent and prolonged time-frame of deteriorating citizen orientations towards politics, it is puzzling why political distrust has been such an under-theorized and neglected concept. ${ }^{1}$ The rich literature in the field of political behaviour has focused almost exclusively on political trust and on developing theories, analytical approaches, and empirical indicators that aim to capture citizen trust in government and support for the political system (see Uslaner, 2017;

\footnotetext{
${ }^{1}$ Exceptions include work by Lenard (2008, 2015), Williams (1998), Ullmann-Margalit (2004), Hart (1978), Bruno (2017), Van De Walle and Six (2014), Intawan and Nicholson (2018), and Hardin (2004), though the treatment of 'political distrust' by the scholars above has been far from consistent. These inconsistencies further indicate the need for a systematic examination of the concept of political distrust offered here. The work of Hay, Stoker, Jennings, and Clarke focusing on 'anti-politics' and public disaffection is also relevant for this discussion (Hay, 2007, 2009; Hay and Stoker, 2009; Jennings and Stoker 2015; Clarke et al., 2018).
} 
Citrin and Stoker, 2018 for a review of the most recent scholarly work). ${ }^{2}$ This article breaks with this approach by focusing on the concept of political distrust, providing an investigation into its nature, meaning, and function and its precise relation to political trust, an exercise that has been long-overdue and has hampered a number of discussions in empirical research regarding the implications of distrust for democratic politics.

The political trust literature has been consistently ambiguous in its approach to distrust. Firstly, there is a disagreement whether citizen distrust of government is inimical to democracy, as the theory of system support and political culture would suggest (Easton, 1965), or whether, following liberal political theory and Madisonian political thought, it is a welcome and necessary citizen stance to ensure democratic survival (Hardin, 2002a; 2004; Warren, 2006; Lenard, 2008; Bruno, 2017). Second, the conceptual status of distrust has been brushed aside on the premise that it is simply the weakening of political trust. In most scholarly work, distrust has been equated with the absence of trust and, therefore, has seldom been considered or theorized in its own right. Although there are 'as many conceptualizations of trust as there are disciplines in the social sciences' (Cook and Santana, 2017, p. 253) and definitions abound, the overarching assumption has been that a theory of trust entails a theory of distrust. As a result, there has been little examination of the precise relationship between the two concepts.

Recent scholarship has begun to draw attention to this omission, highlighting the need to better understand the status of distrust and to study its relationship to trust conceptually and empirically (Hardin, 2004; Van De Walle and Six, 2014; Catala, 2015; Krishnamurthy, 2015; Intawan and Nicholson, 2018). It is unclear however, whether all scholars have the same concept in mind when formulating their arguments. As a case in point, Lenard (2008) and Bruno (2017) have spoken about distrust towards people in a position of political power in the context of institutional design and democratic theory, claiming that trust and distrust can be thought of as 'complementary attitudes' both necessary and both present in democratic systems. Ullmann-Margalit (2004) referred to individual attitudes towards other agents when she described trust and distrust as two ends of a single continuum separated by the state of 'trust agnosticism'. While Van De Walle and Six (2014) and Intawan and Nicholson (2018) argued that trust and distrust are two separate constructs, with different antecedents and implications, the former looking to the literature of public administration and the latter to cognitive psychology to support their claims.

In this article, I focus exclusively on the ontological status of political distrust (as opposed to distrusting attitudes in general $)^{3}$ but draw from wider existing theories of trust and treatments of distrust in order to provide a systematic analysis of the relationship between the two concepts. I argue that treating trust and distrust as equivalent and conflating distrust with the lack of trust is inaccurate and problematic, both conceptually and empirically. The lack of trust is the opposite of trust. Similarly, lack of distrust is the opposite of distrust. Lack of distrust does not extend to encompass relations of trust and lack of trust shouldn't be extended to include relations of distrust, even if in everyday language it is often used in this way. As a result, theorizing and studying political trust does not necessarily tell us what we need to know about the nature, formation, dangers, and possible remedies for political distrust. Although many similarities remain between the two concepts, the aim of this article is to highlight the asymmetries and advance a conceptualization of political distrust, so that future scholarship can proceed with more clarity in its treatment of trust and distrust.

\footnotetext{
${ }^{2}$ While two exceptional edited volumes on Political Trust have been published in recent years (Uslaner, 2017; Zmerli and Van Der Meer, 2017), none of them includes an entry dedicated to political distrust and its relation to trust.

${ }^{3}$ The role of another form of trust, namely generalized social trust or social capital, for good democratic governance and system stability should not be overlooked. Nevertheless, in the space of this article I focus on political trust and distrust, and follow Uslaner (2017), Warren (2017), Cook and Gronke (2005), and Newton, Stolle and Zmerli (2017) among others, who view political trust as fundamentally different in nature from social capital and argue it needs to be theorized separately. Undoubtedly, the two are related - even causally related - but the precise direction of causality has given rise to a lengthy debate (for a summary, see Newton et al., 2017).
} 
The article proceeds as follows. The next section addresses the question of whether political distrust is benign or whether it is dangerous and poses a problem for democratic politics. Arguing that it does so, the section also outlines the definition of political distrust for the purposes of studying citizen behaviour and democratic politics, as a negative attitude held by an individual towards her political system or its institutions and agents. The section that follows presents a theory and conceptual model for political distrust that draws upon existing work. The proposed conceptualization of political distrust here is as an attitude based on three underlying dimensions of technical, ethical, and interest-based evaluations, with distinct functions and implications. The article then tackles the conceptual relationship between political trust and distrust, outlines the similarities and asymmetries between the two concepts, and argues that the most appropriate conceptual treatment is to consider them as two distinct, but strongly related, concepts. The article concludes with a discussion of the contributions made for enhancing scholarly understanding of political distrust and for considering remedial actions.

\section{The trouble with political distrust}

While the role of distrusting attitudes towards government has been debated for decades, the dissonance between empirical observations of citizen distrust of politics and the theoretical approaches used to study citizen orientations towards their political system have become more pressing in the past years. The tentative answers reached by the 'critical citizens' thesis in the late 1990s, which attributed decreasing political trust and rising disaffection to citizens' higher democratic expectations, are being challenged (Norris, 1999). It is possible that the main argument, that as long as citizens in established democracies remain committed to democratic regime principles and processes, distrusting attitudes towards specific authorities would not erode diffuse system support, needs to be revisited in the light of current developments (Citrin, 1974; Miller, 1974; Norris, 2011; Dalton and Welzel, 2014). Nevertheless, without a theory of political distrust and an understanding of what distrust means and how it functions, it is difficult to interpret phenomena of distrust and survey evidence. Already in 1978, in her book Distrust and Democracy, Vivien Hart noted that 'there is no disagreement that substantial numbers of people in both Britain and America now disparage politics. The disagreement is over the significance of this fact - over what political distrust means for those who express it, and whether it means the same, for each of these polities' (1978: 2). The aim of this article is to highlight where theories of trust fail to enlighten the concept of distrust and the consequences of these limitations. It offers an indepth examination of the relationship between the two concepts for the realm of politics and proposes an analytical approach to political distrust that can be used by scholars in the field.

While research in comparative politics and political culture has focused on the role and benefits of political trust, it has largely neglected political distrust. David Easton's Systems of Political Life (1965) provided the theoretical basis for most modern scholarship in the field and defined citizen trust as part of the system's support, which is essential to counterbalance the demands citizens place upon it. According to Easton $(1965,1975)$, political trust is a measure of diffuse support, a 'reservoir of good-will' that sustains the system even when satisfaction with specific incumbents or outcomes (i.e. specific support) may be wanting. Additional work on political and social trust among different democracies has shown how low trust, among other attitudes and individual characteristics, increases political instability and delegitimize political processes by promoting non-cooperation and non-compliance with policies (Hetherington, 1998, 2005; Scholz and Lubell, 1998; Hetherington and Husser, 2012), or abstention from electoral process and a retreat from the public domain (Bélanger and Nadeau, 2005; Hooghe et al., 2011; Marien and Hooghe, 2011; Norris, 2011). ${ }^{4}$

\footnotetext{
${ }^{4}$ Undoubtedly, political distrust is not the only cause of disaffection and non-participation in politics. Many individual-level characteristics, such as education, personal well-being, social status, and many other political attitudes, such as dislike of politics, sense of duty and ideological positioning, contribute to these phenomena (Norris, 2011). Trust-related research has shown that attitudes of trust and distrust are one contributing factor.
} 
Nevertheless, the theoretical discussions that have focused on distrust have often obscured the damaging effect of political distrust for system stability and have followed three main lines of argument. One stems from liberal political theory (and more recently, organizational theory), which welcomes distrust of politicians and officials as necessary for democracy (Hardin, 2002b; Van De Walle and Six, 2014; Bruno, 2017). The second argues that distrust is devoid of any moral connotation and therefore it cannot be considered 'inimical', 'detrimental', or a 'threat' to democracy (Levi, 1997). Finally, the third argument relates to warranted distrust, that is when citizens distrust for good reason, and includes an insightful strand of research that has focused on the distrust felt by marginalized groups within societies. In the following text, I consider each argument in turn, with the aim of showing that citizen attitudes of political distrust in established democracies remain worrisome and should ring alarm bells for scholars interested in democratic stability.

The idea of distrust as 'guardian of democracy' can be traced back to the liberal democratic tradition of Madison, Hume, and Bentham (Parry, 1976; Pettit, 1997; Warren, 1999; Hardin, 2002a, 2002b; Lenard, 2008). Citizens are urged to be suspicious and vigilant towards institutions and people in a position of power, because that power could be used to serve interests other than those of the community (Skinner, 1995; Levi, 1997). Because of the power imbalance and the inevitable corruptibility of human nature, which may lead officials to abuse their position, such suspicion is necessary and a key aspect in the institutional set up of democratic systems. Scholars have attempted to illuminate this paradox, that is the need for both trust and distrust for democratic governance (Lenard, 2008; Bruno, 2017). Despite the thorough accounts they present, their discussion is always framed as a justification for the development of institutional safeguards to be imposed upon office holders and powerful institutions with the aim of limiting their ability to abuse their position.

I maintain that this liberal distrust should not be conflated with the phenomenon of political distrust observed currently in established democracies, which already have in place such checks and balances, monitoring institutions, controls of government actions, and working constitutions. Democratic systems need to 'institutionalize distrust', to acknowledge and manage this conflict of interests through the aforementioned institutional mechanisms in line with classical theory (Warren, 2017). However, after these are in place, what is needed for the system to function is political trust. While liberal distrust is motivated by the need for vigilance, its contribution to democracy lies in demonstrating the institutional and organizational requirements that can ultimately combat perceptions of political untrustworthiness. Its aim is precisely to avoid the creation of a distrusting citizenry, which would impede effective governance and the achievement of cooperation and collective goods in the community.

The need for controls is similarly obfuscated with the presence of distrust in studies of public administration and organizational theory (Van de Walle and Six, 2014). The presence of controls in instances of power imbalances, and selfish motives should not be equated with distrust; distrust of government and of the entire political system takes hold in the absence or malfunction of democratic controlling mechanisms. This would be the same in all organizations and institutions, such as schools, hospitals, and even firms. Given the power imbalance between the state and its citizens, it is the presence and effectiveness of checks and balances that makes it possible for citizens to trust their government, their public officials, their institutions, and the political processes in modern states, allowing them to proceed with their everyday life.

This is an important distinction. If citizens express distrust after these institutional mechanisms have been put in place, this would signify one of the two following alternatives: either the people inhabiting government and the outcomes produced by the political system are perceived to be untrustworthy or - worse still - the very institutional mechanisms for checks and balances are perceived to be inadequate and malfunctioning. In both of these cases, political scientists and democratic theorists need to take note and study distrust further.

Therefore, arguments in favour of the compatibility and necessity of both trust and distrust in the realm of politics, or claims that 'trust is good, but distrust is better' (Hardin, 2002a; Lenard, 2008; 
Bruno, 2017), unfortunately, mix up two very different requirements in a democratic system: the need for vigilance (liberal distrust), which leads to the design and inclusion of safeguards, and the need for political trust, which leads to effective governance and system stability. When the safeguards and controlling mechanisms fail, then the two may coincide and the first order of business should be to reform and strengthen such institutional mechanisms (which can be challenging in a climate of distrust). However, if such mechanisms are present and functioning properly, then classical theory cannot help us to interpret citizens' distrust nor point to the remedial action needed to counter it. For this reason, an encompassing theory that focuses on political distrust is necessary.

The second and third types of argument, which challenge the view of political distrust as detrimental to democratic governance, are inter-related. They claim that there is no inherent moral value to be assigned to either trust or distrust because, when justified, trust and distrust are both benign (Levi, 1997; Hardin, 2002a). This stems from the relational nature of trust and distrust. Trusting an untrustworthy person to, for example, sell you a good quality car or take care of your young kids can be very damaging to you and those who depend on you. Distrusting untrustworthy agents is not only the appropriate approach, but it could even be morally justified as the 'right thing' to do. Further, in cases where distrust is not warranted and one distrusts a trustworthy agent, there is still no moral claim to be made. The only cost to consider is the forgone gain from the cooperation that was impeded by the presence of distrust.

Transferring this reasoning to the realm of politics and citizen-state or citizen-government relations, extending trust to an untrustworthy government or institutions can be detrimental for the citizen and the entire political community. Yet, in the context of a trapped relationship, as are most citizen-state and citizen-system relations, forced exposure to and reliance on untrustworthy agents have negative implications. Think about the potential for disruption in a community where all car salespeople are considered untrustworthy. Distrust towards untrustworthy actors is helpful when these can be replaced, by the active participation, mobilization, and functioning of other important democratic institutions of accountability and sanctioning. Citizens may be right to be distrustful of an untrustworthy politician, a malfunctioning political institution, or a specific political process, but this will be beneficial for democratic governance overall only if untrustworthiness can be contained: if the specific actor can be replaced or the institution can be reformed so as to uphold democratic norms. However, if one government after another or one incumbent after another is perceived untrustworthy, then the entire process of election and accountability will eventually be perceived as malfunctioning. Correcting this is often a challenging endeavour, as research into corruption and the persistence of political distrust has shown (Anderson and Tverdova, 2003; Anduiza et al., 2013). Furthermore, the cost of distrusting a trustworthy agent is much higher in the realm of politics than simply the forgone gain of cooperation, because distrusting citizenries impede the ability of governments to enact policies and govern effectively.

Perhaps the most convincing argument for the positive impact of political distrust when warranted stems from the distrust of marginalized or minority groups toward majority groups and existing unjust order (Fricker, 2009; Catala, 2015; Krishnamurthy, 2015; Lenard, 2015). If political distrust is reasonable, as is often the case with marginalized groups that are discriminated against and have to face unjust laws, then distrust and the subsequent actions it motivates - of protest, disobedience, and disregard for those laws - may help to bring change that improves society and strengthens democracy. ${ }^{5}$ Similarly, the 'critical citizens' thesis, which considered political distrust as a product of increased and unmet democratic expectations of citizens, suggested that pressure and protest can help bring about changes that reflect those higher aspirations

\footnotetext{
${ }^{5}$ Interestingly, empirical evidence show that minority groups routinely exhibit stronger political trust compared to majority groups in established democracies (although they have weaker social capital and lower social trust). The African-American community in the US is an exception to this and it serves as the basis for much of the aforementioned work that focus not only on minority groups but specifically on groups that have been historically discriminated against. See Wikes and Wu (2017) for a review of the field.
} 
(Norris, 1999; Dalton and Welzel, 2014). While evidence does not lend support to the latter thesis, in that trust did not rebound among established democracies (Norris, 2011), both strands of work on warranted distrust point to the function of distrusting attitudes and behaviour as a corrective to democracy. Yet, they also serve to support the argument advanced here, namely that it is paramount to study political distrust expressed by citizens, conceptually and empirically, understand when it is justified and how to remedy it through democratic means. ${ }^{6}$ Long-term overlooked distrust will eventually destabilize a democratic system, which requires the goodwill and cooperation of citizens to function effectively.

Political distrust can be thought of as the machine monitoring the vital signs of a patient. Of course, it is great to know that the machine is working and produces accurate readings, but if the patient (democratic system) is still crashing, there is legitimate reason for concern and need for action. The aim is not to prove political distrust is calamitous in its own right or that it needs to be suppressed. On the contrary, its presence reflects real and/or perceived shortcomings in the set-up, functioning and produced outputs of a political system. Furthermore, because trust and distrust are both cyclical and selfreinforcing, distrust can create a vicious cycle (Sztompka, 1999). Governments can hardly govern effectively when large parts of the citizenry distrust them, further contributing to poor conduct and perceptions of political untrustworthiness, which in turn result in citizens themselves limiting their reliance and vulnerability by cutting ties with political agents and processes. These attributes of political distrust exacerbate existing shortcomings in democratic systems and therefore, as I elaborate in the following section, demand scholarly attention.

\section{A theory of political distrust for political behaviour}

If citizen distrust of government does pose a danger for the healthy functioning of democratic systems, the lack of conceptual clarity and empirical focus on political distrust is, at the very least, peculiar. Given the early emphasis on the necessity of trust, scholarly work has focused primarily on the 'positive end' of the concept, largely disregarding what sits at the negative end of that continuum, or in fact, questioning whether it even is a continuum (Goertz, 2006). The main assumption has been that theories of trust entail within them a theory of distrust. And while many theories of trust are informative, political distrust has remained the object of much confusion and scholarly disagreement, without a clear answer as to how it should be treated. Even Russell Hardin claimed that while trust is not necessary, what is important for democracy is for citizens to not 'actively' or 'deeply distrust' government (2002a: 158,155), but then he stops short from explaining what this deep or active distrust entails. While some scholars conceptualized political trust as a continuum, they often conflated distrust with other attitudes, such as cynicism, alienation, or disaffection (Miller, 1974; Abramson, 1983). Overall, works that have endeavoured to address the problem of distrust have had to grapple with a number of inconsistencies as they attempted to stretch a theory of trust, often beyond its limits, to fit distrust (Hardin, 2004; Lenard, 2008). As a result, empirical measurement and analysis have also confounded distrust with low trust or the absence of trust, and in certain cases tried to separate the two providing different labels, such as 'skeptical', 'critical', or 'neutral' attitudes (Mishler and Rose, 1997; Norris, 1999, 2011; Cook and Gronke, 2005). The neglected status of political distrust in existing theoretical treatments has also resulted in confusion when it comes to empirical research, as scholars

\footnotetext{
${ }^{6}$ For example, Melissa Williams (1998) traces the basis for political distrust among marginalized groups in the lack of political representation and perceived incongruence of interests between these groups and political representatives. She is therefore able to make a clear case for increased descriptive representation to combat distrust.
} 
do not agree on what political distrust denotes, how to best measure it, and how to interpret the signals they do observe empirically (Levi and Stoker, 2000). ${ }^{7}$

Can existing theories of trust be extended to include distrust, and do they transfer to the realm of politics? I argue that most analytical approaches to trust extend as far as the lack of trust, and therefore cannot provide a comprehensive account of distrust. Of course, there are many similarities between trust and distrust, and theories of trust do provide plentiful insights about the nature and function of distrust. However, they do miss critical differences between the two. Examining political distrust in its own right allows us to see these differences clearly and then make a conscious and informed choice about how to best treat the two concepts. In the following paragraphs, I consider the insights and shortcomings of the most prominent theories of (political) trust in their treatment of distrust.

Firstly, Easton's conceptualization of political trust as part of diffuse system support has underpinned most scholarly work in comparative politics. Yet his approach offers no insights on the standing of political distrust, apart from the fact that it would contribute to a lack of diffuse support that can lead to system destabilization. Second, Hardin's influential strategic approach to trust has been extended to include distrust, but not without difficulties (2002a, 2004). This approach focuses on a rational analysis of an agent's capabilities and motivation for acting in a manner that reflects - or 'encapsulates' - the other's interests. The tripartite relationship according to this analytical approach is 'A trusts B to do X'. Therefore, the decision to trust depends on the cognitive exercise of determining whether an agent's capacities and intentions would lead them to behave in a way that satisfies your interest, based on the information available to you (Uslaner, 2017). Given these epistemic demands, trust relationships can only be specific to the domain and task at hand, they cannot be generally extended to the realm of institutions or citizen-state relations. Most importantly, however, the limitation of the strategic approach is that it fails to differentiate between agents who simply do not encapsulate another's interest from agents who aim to threaten or harm another's interests (Hardin, 2004). The latter is an important distinction for distrust. The grammatical sentence 'A distrusts $\mathrm{B}$ to do $\mathrm{X}$ ' is no more informative than 'A does not trust $\mathrm{B}$ to do $\mathrm{X}$ ', implying that the absence of trust is equivalent to the presence of distrust. And yet Hardin himself has claimed that distrust is not simply the action an agent takes when choosing not to trust and that in many cases the trusted may choose not to trust, without actually distrusting (Hardin, 2002a).

To circumvent the restrictions placed by the strategic approach, other scholars have advanced an alternative theory of trust that is based on one's views of ethical reciprocity (Braithwaite and Levi, 1998; Uslaner, 2017). This is the idea that shared normative values will impose certain types of behaviour among agents, allowing citizens to extend trust and solve problems of collective action, even when it does not align with their narrow self-interest. This analytical approach can be extended to explain relations of distrust and norms of negative reciprocity. It highlights the cyclical nature of both trust and distrust, explaining how the use of trust reinforces positive norms and increases trust further, while established distrust reinforces negative norms and increases distrust further, setting in motion a 'virtuous' or 'vicious' circle (Levi, 1997; Sztompka, 1999). Further, the violation of such norms of reciprocity renders distrust selfvalidating, leading to widespread and accepted practices that foster untrustworthy behaviour and further distrust (Gambetta, 1988; Blackburn, 1998). While insightful, this approach focuses

\footnotetext{
${ }^{7}$ This discord plagues the study both of political trust and distrust [see the Miller-Citrin debate, 1974 and Citrin and Stoker's most recent review of this field (2018)]. While research in comparative politics has used Easton's conceptualization of trust as a part of diffuse system support, it has treated political trust as expressive in its measurement and left it up to the interpretation of each individual citizen. Globally, the GSS survey item reads: "I am going to name some institutions in this country. As far as the people running these institutions are concerned, would you say that you have a great deal of confidence, quite a lot of confidence, only some confidence, or very little in them?"
} 
on the relations among members of a collectivity and rests on communal norms. This goes some way to elucidate the nature of political trust and distrust, given political institutions and agents operate as part of a collectivity, but it does not take the vertical nature of citizen-state relations into account.

An extensive literature has also focused on horizontal relationships among members of the community, following the theory of social capital (Putnam, 2000). In a similar vein, distrust as the presence of negative norms of reciprocity was equated simply with the absence of social capital. As relationships between community members have deteriorated in many established democracies, recent scholarship is beginning to explore the function and nature of distrusting attitudes that surpass the mere 'absence' of social capital, creating a burgeoning field of work on social and political polarization.

Perhaps the most informative theoretical approach to trust that helps illuminate relations of distrust has been that employed in the work on minority groups. As mentioned in the previous section, scholars focusing on the relations between minority and majority groups have given extensive thought to the concept of distrust. Social identity theory and the dynamics of in-group and out-group formation underpin most of these approaches. All humans are predisposed to trust our own 'kind' and people who are 'similar to us', rather than out-groups (Turner, 1975; Tajfel, 1978; Turner et al., 1994; Brewer, 1999). ${ }^{8}$ The existence of in-group and out-group bias shows that 'members of an in-group tend to perceive other in-group members in generally favourable terms, particularly as being trustworthy, honest and cooperative' (Messick and Brewer, 1983: 27-28, emphasis in the original). Similarly, members of out-groups are approached with suspicion and hostility and are more likely to be viewed as untrustworthy and un-cooperative.

Social identity theory helps to elucidate the phenomenon of distrust, as opposed to only the lack of trust. Both trust and distrust are described as relational constructs that depend on the delineation of in-groups and out-groups, their level of homogeneity, and relative strength (Brewer, 1999; Kramer, 1999). In the political context, individuals that identify with a group systematically excluded from advocating its interests or holding positions of authority will distrust the state and its agents (Williams, 1998; Krishnamurthy, 2015), while in divided communities, citizens will show strong distrust when positions of power are held by in-group members and strong distrust when these are held by out-group members.

Therefore, rather than a clear comprehensive theory for political distrust, we have a number of insights and partial theoretical treatments we need to synthesize and amend in order to provide an account of distrusting attitudes held by citizens towards their political system. A conceptualization of political distrust needs to draw attention to the following key elements: the fact that distrust is relational and that it characterizes a negative orientation, making it distinct from a neutral or uncertain stance (lack of trust). It needs to clarify the ontological status and meaning of distrust in government, that is the evaluative component of distrusting attitudes, as well as the way it spills over and motivates subsequent action. The remainder of this section proposes a working analytical approach to political distrust that builds upon the theoretical insights discussed above.

\section{Conceptualization of political distrust}

Political distrust can be defined as a relational attitude that reflects perceptions of untrustworthiness specific to the political system in its entirety or its components. The evaluative part of distrusting attitudes is distinctly negative and entails the expectation of harmful outcomes. Distrust is an attitude held by an individual citizen. 'Perceptions of untrustworthiness' are the internal cognitive judgements that (consciously or not) give rise to this attitude. As a second step, actual untrustworthiness refers to the characteristics of the political agents, the government or

\footnotetext{
${ }^{8}$ Some exceptions are Tyler (1998), who considers the role of social identification with the authorities as a source of trust and Hooghe and Marks (2005), who find that communal identities are important in shaping views of political objects, especially in multi-level governance. See also Brewer (1999) for more information.
} 
political system, being evaluated. We would expect - and hope - that citizen perceptions of untrustworthiness match the characteristics of the system, but what is important for the formation of distrust is the way citizens perceive politics.

Perceptions of untrustworthiness can follow three broad types of evaluations: technical incompetence and failure, conduct that violates shared notions of right and fair, and conduct that is incongruent with the citizens' best interest. These evaluative components rest on the empirical and theoretical insights, but they have not been synthesized before to explain the concept of political distrust (Bertsou, 2015; Citrin and Stoker, 2018). Firstly, perceptions of untrustworthiness reflect judgements of technical incompetence. Similarly to the strategic approach to trust, the decision to distrust one's government would be motivated by an examination of its capacity to fulfil tasks. Citizens perceive politics and public offices as posts that require particular types of technical knowledge, competencies, and skills, and know that incompetence in this field has a negative impact on the functioning of the political community. Citizens recognize that governments, state actors, and institutions matter, and that given their roles in a multitude of policy areas, failure to perform according to the needs of the polity impacts citizens in a negative way. Therefore, distrust of a state actor reflects the belief this actor is incapable of fulfilling their technical role requirements. This evaluative dimension of political distrust is sensitive to outputs and governmental performance, which are more easily observable, yet by no means immune to subjective judgements. This component of political distrust as performance evaluation has been highlighted by numerous scholars, who at the same time acknowledge that trust and distrust is much more than just a simple calculation of political track record (Chanley et al., 2000; Hetherington and Husser, 2012; Hetherington and Rudolph, 2015; Citin and Stoker, 2018).

The technical evaluative component of distrust must be supplemented with an ethical one. Political distrust is intrinsically normative, as attitudes of distrust are expressions of the belief that there is something fundamentally wrong, unfair, and unethical about the processes, conduct, and/ or outcomes produced by the political system. Public offices and political functions are perceived untrustworthy when they fail to uphold communal norms of what is 'right', 'just', and 'good'. Precisely because of the power asymmetry between government and the governed, political functions come with a clear set of shared normative values. These moral norms transcend the preference framework of any one individual; they are 'objective' or at least commonly agreed upon by the entire political community. Citizen distrust makes a profound moral claim and highlights the violation of such shared normative values. Distrust stemming from the betrayal of previously extended trust - as is often the case in political evaluations - carries with it an even stronger moral judgement.

It might not be surprising that moral norms play an important role in citizens' evaluations of their political system. Earlier scholarly discussions of what constitutes a trustworthy government and 'good type' of politician have identified qualities that have strong ethical dimensions: honesty, fairness, integrity, and impartiality (Mansbridge, 2003). Referring back to the power imbalance and the possibility that people or institutions could abuse that power, ethical evaluations play such an important role in the orientation of citizens towards their state. Political conduct that is perceived to be wrong, decisions that are unjust, processes and outcomes that are judged to be unfair whether or not these are also deemed to violate institutional checks - will often underpin citizen expressions of political distrust. Distrusting attitudes lay claim to the violation of 'universal' ethical norms, despite the fact that each citizen's evaluative and cognitive framework differs and different cultures may uphold diverse shared values. Crucially, existing research into the moral element of attitudes and beliefs has shown that attitudes based on moral convictions are held much more fervently and are much more resistant to change than other types (Skitka, 2014). Work on the role of procedural justice has also highlighted the role that perceptions of fairness play when citizens decide to trust politics and accept political outcomes as legitimate (Tyler and Jackson, 2014).

Finally, distrusting attitudes entail a third evaluative component that reflects perceptions of incongruent interests between the citizen and the political system or its agents. Based on the 
relational nature of distrust and the insights brought by social identity theory, political distrust reflects the belief that the interests pursued by the political system, the government and its agents, are incongruent with your interests, and hence their actions will prove harmful. This judgement often uses the perceived distance between citizens and political agents as a shorthand. As mentioned in the previous section, the existence of positive and negative norms of reciprocity (such as 'special relationships') are often motivated less by considerations of functional competencies or moral norms and more by proximity and congruence. This evaluative component of distrusting attitudes becomes prominent in divided communities, polarized politics and divisive social issues. Interests can be framed on the basis of geographical, ethnic, religious, ideological, or class differences and understood in either individual or group terms, but the latter provide powerful ground for political distrust.

In deeply divided communities along ethnic, religious, or partisan lines, expressions of political distrust largely entail evaluations of incongruent interests. Examples would include distrust of a government that is run by political parties a citizen opposes, or distrust in a political system that systematically discriminates against the group a citizen belongs to (Bertsou, 2015; Krishnamurthy, 2015). Empirical research findings consistently show that government is distrusted more by citizens who support the opposition, and trust levels switch according to partisan identity once there is a government change (Hetherington and Rudolph, 2015; Citrin and Stoker, 2018). Interestincongruence can also be perceived between citizens and the entire political class or system, for example evaluations of the entire political establishment as disconnected from the citizens, or a system that routinely infringes on the interests of large groups within the community. The messages of populist rhetoric, which portray the entire political elite as corrupt and in sharp contrast to the interests of ordinary people, find fruitful ground and reinforce those who already perceive incongruent interests between themselves and state officials.

Figure 1 shows a diagrammatic representation of the concept of political distrust proposed. The figure depicts the three evaluations of untrustworthiness as partially overlapping to denote that these are not distinct types of political distrust. Ontologically, they represent aspects of distrusting attitudes based on different judgements, which are complex, overlapping, and merged together. Perceptions of untrustworthiness invariably boil down to one or a combination of these three evaluations. More often than not, citizens who distrust their government on the basis of incongruent interests will also perceive this government as unethical and technically incompetent. Corruption, bribery, and cronyism, which are diagnoses of untrustworthy political actors and institutions and, therefore, strongly associated with political distrust, often involve the violation of shared ethical norms, an inefficient and dysfunctional state and an infringement on the bestinterest of the citizens. Interestingly, when evaluations point towards different directions, citizens are responsible for synthesizing information and merging their evaluations in a single judgement. A technically incompetent government that is not perceived to act unethically or infringe on a citizens' best-interest will not be distrusted equally to one that does so. Context is also expected to matter when it comes to the relative weight citizens will place on the evaluative components. As mentioned above, in deeply divided societies interest-congruence is paramount, while in communities that have been shocked by a political scandal ethical judgements will take centre stage.

Citizens use new information, past experience, and existing knowledge about the characteristics of political actors to formulate their evaluations. Importantly, evaluations of untrustworthiness are not causes of distrust, but what distrust signifies for the citizens who express it. Political distrust as an attitude entails an evaluative component on the basis of which expectations of harmful and negative outcomes are formed. Political distrust also has behavioural implications as it is linked to subsequent decisions and actions. We already know that trust and distrust are cognitive and affective notions that become particularly relevant in conditions of risk or uncertainty (Levi, 1997; Fenton, 2000). Trust can help to mitigate risk and bridge uncertainty, so as to allow cooperative relationships, while distrust flags risk, places one in a state of high alert, and motivates action to subvert the vulnerability and reliance on the distrusted agent (Gambetta, 1988; Yamagishi et al., 


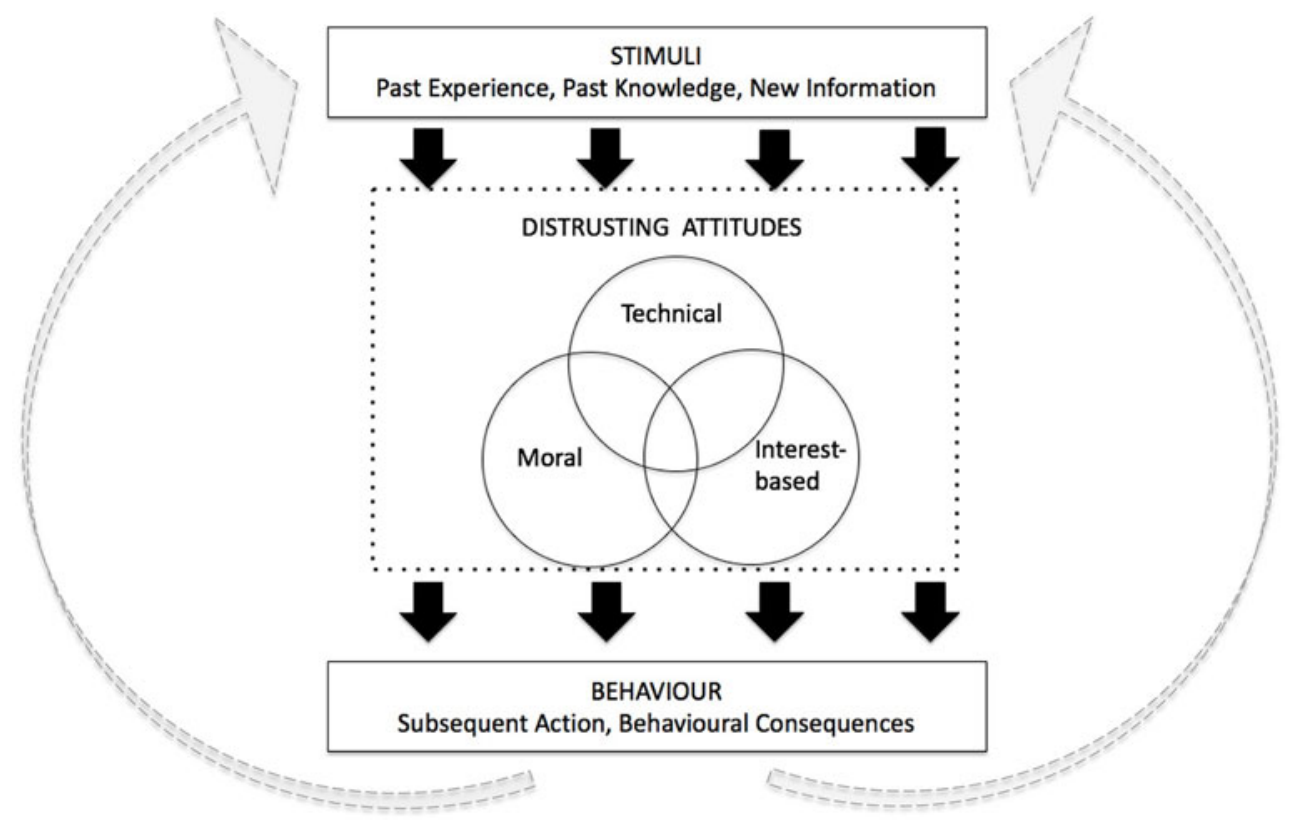

Figure 1. Conceptual model of political distrust.

1998; Schul et al., 2008). In this sense, distrust reflects some certainty about the relation, but it cannot serve to mitigate risk and bridge the two agents. Distrust targeted at political agents motivates hostility, anger, and disappointment and activates a search for ways to terminate interactions with those agents, bypassing them or replacing them. Distrust towards higher level institutions or the entire political system becomes more problematic, as citizens are caught in a trapped relationship where they are still exposed to untrustworthy institutions (unless they decide to leave the country or become an outlaw).

While the object of political distrust is not visible in Figure 1, distrust can be directed towards the entirety of the political system or specific components. Citizens may distrust specific political groups, but this distrust can also spill-over from one political level to another. Though they often differ in their assessment of untrustworthiness, the different parts of a political system seldom operate in isolation. An important characteristic of distrust is its self-reinforcing nature and its spill-over from one political object to another, from incumbents, to processes or institutions and vice versa. The Eastonian approach separates evaluations of incumbents from evaluations of the political system and its institutions. While the separation of citizen orientations towards specific and diffuse political levels is a useful analytical distinction (Miller, 1974; Norris, 1999; Dalton and Welzel, 2014), one would expect that repeated instances of specific distrust within trapped relationships interfere with the strictly hierarchical framework this approach suggests. Perceptions of untrustworthy incumbents and lower level agencies over long periods of time showcase the inability of higher level institutions and processes to combat untrustworthiness. As mentioned in the preceding section, if administration after administration is distrusted by its citizens, the process of selection and election, along with other governmental institutions, will also be perceived as untrustworthy and malfunctioning. Similarly, scandals and crises shape perceptions of certain figures or agencies, but the system's response to such instances also determine whether untrustworthiness can be contained or whether it spills over to higher levels of the political system.

Finally, the cyclical and self-reinforcing characteristics of political distrust contribute to the creation of a vicious circle that feeds itself, denoted in Figure 1 with the cyclical arrows connecting 
behaviour to stimuli. Distrusting political attitudes impede cooperation and interactions that could mitigate distrust, giving rise to political processes that cannot operate effectively and cannot reach out to citizens to mend perceptions of untrustworthiness. This is why distrust is often considered a non self-disconfirming concept (Larson, 1997). Untrustworthy political agents feed distrust and distrust feeds political untrustworthiness, establishing relations of negative reciprocity. Given the multitude of ways in which political agents and processes impact the lives of citizens, political distrust creates incentives for citizens to become themselves untrustworthy citizens, resorting to 'special relationships' and alternative networks for communal life.

\section{Trust and distrust: a contested relationship}

Having given political distrust an encompassing analytical treatment in its own right, it is now possible to turn to the relationship between trust and distrust. In the following paragraphs, I draw attention to the similarities and differences between the two and discuss three separate conceptual treatments that are available for scholars. Starting with the similarities, the conceptualization of political distrust presented in this article shares a lot with the concept of political trust. Both are relational and represent a calculation of the probability of benefit, or harm, from interactions with the political system and its agents. Both are relevant in motivating subsequent action and both are cyclical and self-reinforcing, leading either to a vicious circle of hostility and suspicion or to a virtuous circle of reliance and cooperation. Phenomenally, this makes trust and distrust seem as one and the same concept and justifies treating distrust as simply the lower end of a trust conceptual continuum (depicted as graph a in Figure 2). This has been the treatment followed by much theoretical and empirical research, and which I have tried to argue is unhelpful and inaccurate for a number of reasons.

First, I have already referred to an important semantic asymmetry. The relationship between trust, the lack of trust, and distrust is not a minute etymological detail. It is important both conceptually and empirically. Equating the lack of trust with distrust is equivalent to equating 'something' with the 'absence of something else' (in this case 'harm' with the 'absence of benefit') and assumes low trust and distrust are equivalent notions. 'Expectations of harm' is by definition something and represents a distinct state with particular psychological and behavioural implications. It cannot be assumed to signify simply the 'lack of something positive'. If attitudes of trust denote expectations of benefit in response to political agents, the lack of trust is the absence of such positive expectations. Similarly, lack of distrust should denote the absence of negative expectations.

Second, stemming directly from this semantic asymmetry are two important functional asymmetries. Extensive research in social psychology and behavioural economics has shown that humans do not treat the absence of benefits the same way as the presence of costs or threats (Kahneman and Tversky, 1979). In the same way, while both trust and distrust are relevant for action, trust leads to placing one's self in a position of vulnerability and allows cooperation, but distrust has implications that far exceed the phenomenon of non-cooperation. The psychological and behavioural states entailed in the expectation of harm and losses are fundamentally different from that of an expectation of gain from cooperation, or the lack of any such expectations. In simpler terms, being told you should expect to lose $€ 1000$ or to be punched forcefully puts one in a very different state than if you are told you will not win $€ 1000$ or you will not receive a pat in the back.

Distrust orients citizens towards actions that will protect them from the reach of government and its agents or sever the citizen-state relationship, which ultimately leads to making citizens untrustworthy. 'Untrustworthy citizens' are those who do not fulfil their obligations and do not exercise their rights, adding to a spiral of distrust. A further implication of asymmetry stems from the emotive state entailed in trust and distrust. Whereas political trust signals normalcy and 
(a)
high distrust
high trust/
low distrust
trust-distrust equivalence

(b)

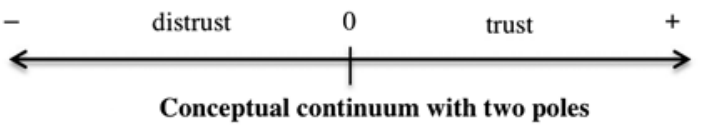

(c)

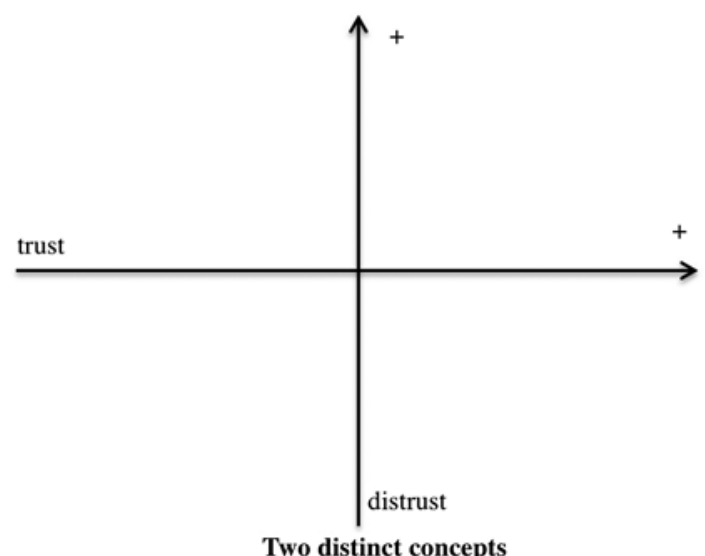

Figure 2. Three conceptual treatments for political trust and distrust (a) trust-distrust as the same concept, (b) conceptual continuum with two poles, (c) two distinct concepts.

allows citizens to proceed with other aspects of their lives, distrust is associated with intense psychological states of anger, anxiety, and even despair, which further influence subsequent action.

Finally, a third functional asymmetry between the two concepts stems from the epistemic needs for trust and distrust. As noted before, both trust and distrust are cyclical and selfreinforcing: trust leading to a virtuous circle of further trust, effective government, and trustworthiness and distrust to a spiral of distrust, ineffective governance, and untrustworthiness. But as the old adage runs, 'it is easier to destroy trust than it is to destroy distrust.' The reason for this is because while trust is self-disconfirming, distrust is not. Misplaced trust will result in distrust once failure or betrayal occurs. But misplaced distrust does not offer opportunities for disconfirmation. Even if it is unjustified, relations of distrust mean one will avoid being put in a position of vulnerability, and hence will not have the necessary information and experiences to dispel distrust. Applied to the realm of politics this asymmetry is particularly important as established distrust gives no opportunities to invest in the political process. On the contrary, if distrust has caused the severing of ties between citizen and the state, through the open defiance of laws and established process or removing one's self from the state's reach, dispelling distrust requires a disproportionate amount of time and effort on behalf of both parties (Gambetta, 1988; Blackburn, 1998).

Table 1 above summarizes the conceptual similarities and differences between trust and distrust that have been discussed. While the similarities are many, the asymmetries identified are also important. The semantic asymmetry (1) highlights the difference between positive-neutralnegative expectations, which should be reflected in the notions of trust-lack of trust and distrust-distrust. Asymmetries (2) and (3) refer to the functional implications of trust and distrust when considering the decision-making processes, behavioural and emotional responses they give 
Table 1. Similarities and asymmetries between political trust and distrust

\begin{tabular}{|c|c|c|c|}
\hline Asymmetries & Conceptual Elements & Political Trust & Political Distrust \\
\hline & Relational and evaluative & $\checkmark$ & $\checkmark$ \\
\hline & Probability calculation & $\checkmark$ & $\checkmark$ \\
\hline (1) Semantic & Expectation of benefit (positive) & $\checkmark$ & \\
\hline \multirow[t]{2}{*}{ Asymmetry } & Expectation of harm (negative) & & $\checkmark$ \\
\hline & Motivating subsequent action & $\checkmark$ & $\checkmark$ \\
\hline (2) Functional & Risk bridging, cooperation, compliance & $\checkmark$ & \\
\hline \multirow[t]{2}{*}{ Asymmetry } & $\begin{array}{l}\text { Retreat, protection, aggression, } \\
\text { untrustworthy citizens }\end{array}$ & & $\checkmark$ \\
\hline & Emotive state & $\checkmark$ & $\checkmark$ \\
\hline (3) Functional & Security, order & $\checkmark$ & \\
\hline \multirow[t]{2}{*}{ Asymmetry } & Fear, anxiety, resentment, despair & & $\checkmark$ \\
\hline & Cyclical and self-reinforcing & $\checkmark$ & $\checkmark$ \\
\hline (4) Functional Asymmetry & Self-disconfirming & $\checkmark$ & \\
\hline
\end{tabular}

rise to. Finally, asymmetry (4) highlights that although both trust and distrust are self-reinforcing, distrust is not self-disconfirming, and hence it is extremely difficult to counter.

Now these asymmetries have not gone entirely unnoticed by scholars in the field, but it is not clear what they mean for the conceptual treatment of trust and distrust. In recognition of the semantic asymmetry between trust and distrust, some political scientists have attempted to distinguish between three states by examining 'skeptical', 'unconvinced' citizens or citizens that both trust and distrust political agents (Mishler and Rose, 1997; Braithwaite and Levi, 1998; Levi and Stoker, 2000). This represents a conceptual treatment with two poles and a distinct neutral state of 'neither trust nor distrust', as shown in graph (b) instead of graph (a) in Figure 2. This is already an improvement, acknowledging the distinctive state of distrust. It does imply, however, that trust and distrust are equidistant from the neutral point and does not deal with the functional asymmetries between the two (Luhmann, 1980, 71).

The three types of functional asymmetries between political trust and distrust outlined above suggest that, strictly speaking, treating the two as part of a bipolar conceptual continuum could lead to a misunderstanding of the function of trust and distrust. Hardin has admitted that trust and distrust are 'functionally very different in their implications for your actions or for social organization' (2002a: 95), comparing their relation to that of the 'on' and 'off parts of an electricity switch. Then the key question is whether the asymmetries identified and the research questions political scientists are interested in warrant a treatment of the two as distinct concepts. This is not unlike questions of conceptualization of terms such as 'well-being' and 'suffering' or 'war and peace' (Goertz, 2006). If political trust and distrust are treated as two separate constructs, then we can use the graphical representation (c) shown in Figure 2. While some research is already making the case for such a treatment, based on the distinct 'fast' and 'slow' systems people use to think about politics (Kahneman, 2011; Intawan and Nicholson, 2018), political trust, and distrust towards the political system should not be considered complementary and therefore cases should fall within the second and fourth quadrants of the two-dimensional Cartesian system. The functional asymmetries that refer to implications of distrust already provide an argument in favour of this conceptual treatment. Causal asymmetries, that is the identification of distinct causes of trust and distrust, would also warrant this approach, as trying to explain or remedy a phenomenon by identifying the causes of a related - but different - phenomenon will inevitably lead to omissions. Although in the space of this article I have not addressed causal questions, given the overwhelming emphasis that research has placed upon the concept of trust, a lot can be gained by investigating the two concepts independently. Lack of trust is surely not equivalent to distrust, and at the very least, treating trust and distrust as two poles of a conceptual continuum should be accompanied by 
the acknowledgement of important functional asymmetries between the two and a focus on the side of the continuum that we aim to investigate.

\section{Conclusion}

Political distrust appears to be the norm in established democracies, and yet its study has been hindered by the theoretical and empirical overreliance on the concept of trust. The scholarly disagreement regarding the ontological status, meaning, role, and function of distrust in democratic contexts has had two repercussions. First, citizen distrust of government and political institutions has not been definitively treated as a problem and threat to the stability of democratic systems - in some cases it has even been interpreted as benign and necessary. Second, political distrust has been hastily equated with low trust or the lack of trust, without a systematic investigation of the differences and asymmetries between the two concepts or the limitations these pose for empirical research.

In this article, I have argued that conflating liberal distrust with political distrust is problematic and usually fails to elucidate current phenomena in democracies that already have functioning constitutions and accountability mechanisms in place. The purpose of this argumentation was not to show that distrust needs to be suppressed or that it is 'wrong' even when it is warranted. On the contrary, the aim was to highlight the need to take note and study political distrust, because - warranted or not - it reflects citizens' perceptions of democratic failures. I have done this by proposing a conceptualization of distrust that entails three evaluative judgements, that is action-motivating and cyclical in nature. Then pitting trust and distrust side by side, the final section of this article highlighted the asymmetries between the two and discussed the implications for further work. Further to the semantic, functional, and epistemic asymmetries explored, future research can focus on the investigation of causal and asymmetries not addressed in this article.

Some additional implications of the conceptual model advanced in this paper include the possibilities for democratic remedies to distrust and enhance our understanding of current phenomena, especially the rising appeal of populist rhetoric and popular backlash against political and technocratic expertise. Perceptions of technical failures and incompetent governance point to the importance of skills, knowledge, and effective political outputs in countering distrust. Recent economic and political failures across Europe have understandably created anger towards detached policy-makers. Combating poor performance is an obvious and uncontested way of combating political distrust, though it is not foolproof. Equally important for the purposes of remedial action is the ethical evaluative dimension of political distrust, which highlights the intrinsic normative nature of distrusting judgements. Distrust based on perceptions of unethical practices and unjust outcomes can be reversed if policy-makers and politicians focus on promoting shared notions of justice and fairness, and even reinforcing the monitoring mechanisms that democracies have in place to limit morally reprehensible conduct. The final evaluative dimension entailed in distrusting attitudes, that of incongruent interests, is more prominent in divided societies and competing groups, but it poses a danger when diverging interests are delineated between the citizenry and the political establishment as a whole. Populist rhetoric finds fruitful ground in conditions of distrust as it contrasts an 'evil' elite that operates against the interests of 'good ordinary people'. Further research in this field is needed to examine these relationships and to understand how distrust can be contained from spilling over to the systemic level or how to combat it once it has generalized.

Acknowledgements. The author would like to thank the following individuals who have provided feedback on this work: Michael Bruter, Sofie Marien, Marc Hooghe, Silja Hausermann, Daniele Caramani, Marco Steenbergen, Malu Gatto, as well as other colleagues at the University of Zurich and the London School of Economics. 


\section{References}

Abramson P. (1983), Political Attitudes in America, San Francisco, CA: Freeman.

Anderson C.J. and Y.V. Tverdova (2003), 'Corruption, political allegiances and attitudes toward government in contemporary democracies', American Journal of Political Science 47(1): 91-109.

Anduiza E., A. Gallego and J. Muñoz (2013), 'Turning a blind eye', Comparative Political Studies 46(12): $1664-1692$.

Bélanger É. and R. Nadeau (2005), 'Political trust and the vote in multiparty elections: the Canadian case', European Journal of Political Research 44(1): 121-146.

Bertsou E. (2015), Citizen attitudes of political distrust: examining distrust through technical, ethical and interest-based evaluations. PhD Thesis. The London School of Economics and Political Science (LSE). Available at: http://etheses.lse. ac.uk/3332/

Blackburn S. (1998), 'Trust, cooperation and human psychology', in V. Braithwaite and M. Levi (eds.), Trust and Governance, New York, NY: Russell Sage, pp. 28-45.

Braithwaite V. and M. Levi (1998), Trust and Governance, New York, NY: Russell Sage Foundation.

Brewer M. (1999), 'The psychology of prejudice: ingroup love and outgroup hate?' Journal of Social Issues 55(3): 429-444.

Bruno J.R. (2017), 'Vigilance and confidence: Jeremny Bentham, publicity and the dialectic of political trust and distrust', American Political Science Review 111(2): 295-307.

Catala A. (2015), 'Democracy, trust, and epistemic justice', The Monist 98(4): 424-440.

Chanley V., T. Rudolph and W. Rahn (2000), 'The origins and consequences of public trust in government: a time series analysis', Public Opinion Quarterly 64(3): 239-256.

Citrin J. (1974), 'Comment: the political relevance of trust in government', American Political Science Review 68(3): 973-988.

Citrin J. and L. Stoker (2018), 'Political trust in a cynical age', Annual Reviews of Political Science 21: 49-70.

Clarke N., W. Jennings, J. Moss and G. Stoker (2018), The Good Politician, Cambridge: Cambridge University Press.

Cook K. and J. Santana (2017), 'Trust and rational choice', in E.M. Uslaner (ed.), The Oxford Handbook of Social and Political Trust, Oxford, UK: Oxford University Press, pp. 253-278.

Cook T.E. and P. Gronke (2005), 'The Skeptical American: revisiting the meanings of trust in government and confidence in institutions', The Journal of Politics 67(3): 784-803.

Dalton R.J. and C. Welzel (2014), The Civic Culture Transformed: From Allegiant to Assertive Citizens, Cambridge: Cambridge University Press.

Easton D. (1965), A Systems Analysis of Political Life, New York, NY: Wiley.

Easton D. (1975), 'A re-assessment of the concept of political support', British Journal of Political Science 5(4): 435-457.

Fenton N. (2000), 'Critical perspectives on trust and civil society', in F. Tonkiss, A. Passey, N. Fenton and L. Hems (eds.), Trust and Civil Society, Basingstoke: Macmillan, pp. 151-173.

Fricker M. (2009), Epistemic Injustice: Power and the Ethics of Knowing, Oxford, UK: Oxford University Press.

Gambetta D. (1988), Trust: Making and Breaking Cooperative Relations, Oxford, UK: Basil Blackwell.

Goertz G. (2006), Social Science Concepts: A User's Guide, Princeton, NJ: Princeton University Press.

Hardin R. (2002a), Trust and Trustworthiness, New York, NY: Russell Sage.

Hardin R. (2002b), 'Liberal distrust', European Review 10(1): 73-89.

Hardin R. (2004), Distrust, New York, NY: Russell Sage.

Hart V. (1978), Distrust and Democracy: Political Distrust in Britain and America, Cambridge, UK: Cambridge University Press.

Hay C. (2007), Why We Hate Politics, Cambridge, UK: Polity Press.

Hay C. (2009), 'Disenchanted with democracy, pissed off with politics', British Politics 4(1): 92-99.

Hay C. and G. Stoker (2009), 'Revitalising politics: have we lost the plot?' Representation 45(3): 225-236.

Hetherington M.J. (1998), 'The political relevance of political trust', American Political Science Review 92(4): 791-808.

Hetherington M.J. (2005), Why Trust Matters: Declining Political Trust and the Demise of American Liberalism, Princeton, NJ: Princeton University Press.

Hetherington M.J. and J.A. Husser (2012), 'How trust matters: the changing political relevance of political trust', American Political Science Review 56(2): 312-325.

Hetherington M.J. and T.J. Rudolph (2015), Why Washington Won't Work: Polarization, Political Trust and the Governing Crisis, Chicago: The University of Chicago Press.

Hooghe L. and G. Marks (2005), 'Calculation, community and cues: public opinion on European integration', European Union Politics 6(4): 419-443.

Hooghe M., S. Marien and T. Pauwels (2011), 'Where do distrusting voters turn if there is no viable exit or voice option? The impact of political trust on electoral behaviour in the Belgian regional elections of June 2009', Government and Opposition 46(2): 245-273.

Intawan C. and S.P. Nicholson (2018), 'My trust in government is implicit: automatic trust in government and system support', Journal of Politics 80(2): 601-613.

Jennings W. and G. Stoker (2015), 'The impact of anti-politics on the general election 2015', Available at http:// sotonpolitics.org/ 
Kahneman D. (2011), Thinking Fast and Slow, New York, NY: Farrar, Straus and Giroux.

Kahneman D. and A. Tversky (1979), 'Prospect theory: an analysis of decision under risk', Econometrica 47: $263-291$.

Kramer R. (1999), 'Trust and distrust in organization: emerging perspectives, enduring questions', Annual Review in Psychology 50(1): 60-98.

Krishnamurthy M. (2015), '(White) Tyranny and the democratic value of distrust', The Monist 98(4): 391-406.

Larson D.W. (1997), 'Trust and missed opportunities in international relations', Political Psychology 18(3): 701-734.

Lenard P.T. (2008), 'Trust your compatriots, but count your change: the roles of trust, mistrust and distrust in democracy', Political Studies 56(2): 312-332.

Lenard P.T. (2015), 'The political philosophy of trust and distrust in democracies and beyond', The Monist 98(4): 353-359.

Levi M. (1997), 'A state of trust', Unpublished paper, University of Washington. Available from: http://www.colbud.hu/ honesty-trust/levi/pub01.PDF

Levi M. and L. Stoker (2000), 'Political trust and trustworthiness', Annual Review of Political Science 3: 475-508.

Luhmann N. (1980), Trust and Power, New York, NY: Wiley.

Mansbridge J. (2003), 'Rethinking representation', American Political Science Review 97(4): 515-528.

Marien S. and M. Hooghe (2011), 'Does political trust matter? an empirical investigation into the relation between political trust and support for law compliance', European Journal of Political Research 50(2): 267-291.

Messick D. and M. Brewer (1983), 'Solving social dilemmas', in L. Wheeler and P. Shaver. (eds.), Review of Personality and Social Psychology (Vol 4), Beverly Hills, CA: Sage, pp. 11-44.

Miller A.H. (1974), 'Political issues and trust in government: 1964-1970', American Political Science Review 68(3): 951-972.

Mishler W. and R. Rose (1997), 'Trust, distrust and skepticism: popular evaluations of civil and political institutions in postcommunist societies', The Journal of Politics 59(2): 418-451.

Newton K., D. Stolle and S. Zmerli (2017), 'Social and political trust', in E.M. Uslaner (ed.), The Oxford Handbook of Social and Political Trust, Oxford, UK: Oxford University Press, pp. 37-56.

NorrisP., (ed) (1999), Critical Citizens: Global Support for Democratic Governance, Oxford, UK: Oxford University Press.

NorrisP., (ed) (2011), Democratic Deficit: Critical Citizens Revisited, Cambridge, UK: Cambridge University Press.

Parry G. (1976), 'Trust, distrust and consensus', British Journal of Political Science 6(2): 129-142.

Pettit P. (1997), Republicanism: A Theory of Freedom and Government, Oxford, UK: Clarendon.

Putnam R. (2000), Bowling Alone: The Collapse and Revival of American Community, New York, NY: Simon \& Schuster.

Scholz J.T. and M. Lubell (1998), 'Trust and taxpaying: testing the heuristic approach to collective action', American Journal of Political Science 42(2): 398-417.

Schul Y., R. Mayo and E. Burnstein (2008), 'The value of distrust', Journal of Experimental Social Psychology 44(5): 1293-1302.

Skinner E.A. (1995), Perceived Control, Motivation and Coping, Newbury Park, CA: Sage Publications.

Skitka L.J. (2014), 'The psychological foundations of moral conviction', in H. Sarkissian and J. Wright (eds.), Advances in Moral Psychology, New York, NY: Bloomsbury Academic Press, pp. 148-166.

Sztompka P. (1999), Trust: A Sociological Theory, Cambridge, UK: Cambridge University Press.

Tajfel H. (1978), Differentiation between Social Groups: Studies in the Social Psychology of Intergroup Relations, London, UK: Academic Press.

Turner J. (1975), 'Social comparison and social identity: some prospects for intergroup behaviour', European Journal of Social Psychology 5(1): 1-34.

Turner J., P. Oakes, A. Haslam and C. McGarty (1994), 'Self and collective: cognition and social context', Personality and Social Psychology Bulletin 20: 454-463.

Tyler T. (1998), 'Trust and democratic governance', in V. Braithwaite and M. Levi (eds.), Trust and Governance, New York, NY: Russell Sage, pp. 269-294.

Tyler T. and J. Jackson (2014), 'Popular legitimacy and the exercise of legal authority: motivating compliance, cooperation, and engagement', Psychology, Public Policy and Law 20(1): 78-95.

Ullmann-Margalit E. (2004), 'Trust, distrust and in between', in R. Hardin (ed.), Distrust, New York, NY: Russel Sage, pp. 60-82.

Uslaner E.M. (2017), The Oxford Handbook of Social and Political Trust, Oxford, UK: Oxford University Press.

Van De Walle S. and F. Six (2014), 'Trust and distrust as distinct concepts: why studying distrust in institutions is important', Journal of Comparative Policy Analysis: Research and Practice 16(2): 158-174.

Warren M.E. (1999), Democracy and Trust, Cambridge, UK: Cambridge University Press.

Warren M.E. (2006), 'Democracy and the state', in J. Dryzek, B. Honig and A. Phillips (eds.), The Oxford Handbook of Political Theory, Oxford, UK: Oxford University Press.

Warren M.E. (2017), 'Trust and democracy', in E.M. Uslaner (ed.), The Oxford Handbook of Social and Political Trust, Oxford, UK: Oxford University Press, pp. 75-94.

Wilkes R. and C. Wu (2017), 'Trust and minority groups', in E.M. Uslaner (ed.), The Oxford Handbook of Social and Political Trust, Oxford, UK: Oxford University Press, pp. 231-252. 
Williams M.S. (1998), Voice, Trust and Memory: Marginalized Groups and the Failings of Liberal Representation, Princeton, NJ: Princeton University Press.

Yamagishi T., K. Cook and M. Watabe (1998), 'Uncertainty, trust and commitment formation in the United States and Japan', American Journal of Sociology 104(1): 165-194.

Zmerli S. and T.W.G. Van Der Meer (2017), Handbook of Political Trust, Cheltenham: Edward Elgar Publishing.

Cite this article: Bertsou E (2019). Rethinking political distrust. European Political Science Review 11, 213-230. https:// doi.org/10.1017/S1755773919000080 